\title{
Hydroxy double salts loaded with bioactive ions: Synthesis, intercalation mechanisms, and functional performance
}

Abdessamad Y A. Kaassis, ${ }^{\text {a }}$ Si-Min Xu, ${ }^{\mathrm{b}}$ Shanyue Guan, ${ }^{\mathrm{b}}$ David G. Evans, ${ }^{\mathrm{b}}$ Min Wei, ${ }^{\mathrm{b} *}$ and Gareth R. Williams ${ }^{\mathrm{a} *}$

a UCL School of Pharmacy, University College London, 29-39 Brunswick Square, London, WC1N 1AX, UK.

b State Key Laboratory of Chemical Resource Engineering, Beijing University of Chemical Technology, Beijing 100029, P. R. China

* authors for correspondence. Email: weimin@mail.buct.edu.cn (MW); g.williams@ucl.ac.uk (GRW); Tel: +86 (0)106 4412131 (MW): +44 (0)207 7535868 (GRW).

\section{Abstract}

The intercalation of the anions of diclofenac (Dic), naproxen (Nap), and valproic acid (Val) into three hydroxy double salts (HDSs) has been explored in this work. Experiments were performed with $\left[\mathrm{Co}_{1.2} \mathrm{Zn}_{3.8}(\mathrm{OH})_{8}\right]\left(\mathrm{NO}_{3}\right)_{2} \cdot 2 \mathrm{H}_{2} \mathrm{O} \quad\left(\mathrm{CoZn}-\mathrm{NO}_{3}\right), \quad\left[\mathrm{Ni}_{2} \mathrm{Zn}_{3}(\mathrm{OH})_{8}\right]\left(\mathrm{NO}_{3}\right)_{2} \cdot 2 \mathrm{H}_{2} \mathrm{O} \quad\left(\mathrm{NiZn}-\mathrm{NO}_{3}\right) \quad$ and $\left[\mathrm{Zn}_{5}(\mathrm{OH})_{8}\right]\left(\mathrm{NO}_{3}\right)_{2} \cdot 2 \mathrm{H}_{2} \mathrm{O}\left(\mathrm{Zn}-\mathrm{NO}_{3}\right)$. It proved possible to intercalate diclofenac and naproxen into all three HDSs. In contrast, Val could be intercalated into $\mathrm{CoZn}-\mathrm{NO}_{3}$ but when it was reacted with $\mathrm{Zn}$ $\mathrm{NO}_{3}$ the HDS structure was destroyed, and the product comprised $\mathrm{ZnO}$. Successful intercalation was verified by X-ray diffraction, IR spectroscopy, and elemental microanalysis. Molecular dynamics (MD) simulations showed the Dic and Nap ions to arrange themselves in an " $\mathrm{X}$ " shape in the interlayer space, forming a bilayer. Val was found to adopt a position with its aliphatic groups parallel to the HDS layer, again in a bilayer. In situ time resolved X-ray diffraction experiments revealed that intercalation of Dic and Nap into CoZn- $\mathrm{NO}_{3}$ and $\mathrm{Zn}-\mathrm{NO}_{3}$ is mechanistically complex, with a number of intermediate phases observed. In contrast, the intercalation of all three guests into $\mathrm{NiZn}-\mathrm{NO}_{3}$ and of Val into $\mathrm{CoZn}-\mathrm{NO}_{3}$ are simple one step reactions proceeding directly from the starting material to product. The HDS-drug composites were found to have sustained release profiles.

\section{Introduction}

Layered metal hydroxides (LMHs) are a broad family of materials which have much potential in the delivery of biologically active species. Two commonly occurring types of LMH are hydroxy double salts (HDSs) and layered double hydroxides (LDHs). These have the same key structural features of positively charged layers and charge-balancing anions located in the interlayer region, but they differ in their layer compositions. LDHs contain a mixture of trivalent and mono or divalent metal cations, ${ }^{1-4}$ while HDSs contain only divalent metal cations. ${ }^{5-7}$ The generic formula of an HDS is 
$\left[\left(\mathrm{M}^{2+}{ }_{x-1} \mathrm{Me}^{2+}{ }_{x}\right)(\mathrm{OH})_{3(1-y)}\right] \mathrm{X}_{(1+3 y) / n}^{\mathrm{n}-} \mathrm{ZH}_{2} \mathrm{O} . \mathrm{M}$ and $\mathrm{Me}$ are divalent metal ions such $\mathrm{Zn}^{2+}, \mathrm{Cu}^{2+}, \mathrm{Ni}^{2+}$, or $\mathrm{Co}^{2+}, 8,9$ and $\mathrm{X}$ is an anion such as $\mathrm{Cl}^{-}, \mathrm{NO}_{3}{ }^{-}$, or $\mathrm{CO}_{3}{ }^{2-9,10}$ The latter can be replaced, through an ion exchange route, with a variety of inorganic and organic anions. ${ }^{11-14}$

LDHs have attracted the interest of many researchers for their potential as drug delivery systems. They have been widely explored in vitro and in vivo for drug delivery and LDHs loaded with active pharmaceutical ingredients (APIs) have shown improved properties over the free drugs in terms of solubility, absorption, bioavailability and cellular uptake. ${ }^{15-22}$ However, much less attention has been paid to HDSs in general and specifically to their potential as delivery systems. The few studies which have been reported suggest that HDSs may have improved properties than LDHs in this regard. HDSs have been intercalated with mefenamate, indole-3-acetate, 4-biphenylacetate, 4-(2,4dichlorophenoxy) butyrate and 2-(3-chlorophenoxy) propionate and in all cases the guests were released from the HDS hosts over a prolonged period of time, with slower release than observed with $\mathrm{LDHs}^{7,23,24}$

In this work, a range of carboxylic acid drugs were explored. These can easily form anions suitable for intercalation. The anti-inflammatory, analgesic, and antipyretic drugs diclofenac (Dic) and naproxen (Nap), together with the anticonvulsant and mood stabilizing active ingredient valproic acid (Val), were selected for investigation. The structures of these drugs are given in Figure 1.<smiles>N#CC(=O)Cc1ccccc1Nc1c(Cl)cccc1Cl</smiles>

Dic<smiles>COc1ccc2cc([C@@H](C)C(=O)[O-])ccc2c1</smiles><smiles>CCCC(CCC)C(=O)[O-]</smiles>

Figure 1: The chemical structures of Dic, Nap and Val .

These guests were incorporated into a range of Zn-containing HDSs, and the resultant intercalates fully characterised. An in situ X-ray diffraction study was performed to investigate the intercalation mechanisms and kinetics. Molecular dynamics simulations were undertaken to aid interpretation of the diffraction data. Finally, the release of the drugs was studied in simulated physiological conditions.

\section{Experimental section}




\subsection{Synthesis}

\subsubsection{Materials}

Zinc oxide, zinc chloride, zinc nitrate hexahydrate, cobalt (II) nitrate hexahydrate, and nickel (II) nitrate hexahydrate were supplied by Fisher Scientific; $99 \%$. Diclofenac sodium (Dic) was sourced from Cambridge Bioscience, and naproxen sodium (Nap) and valproate sodium (Val) were purchased from Sigma-Aldrich.

\subsubsection{HDS synthesis}

The HDSs were synthesised using methods reported previously. ${ }^{10}$ The reaction mixtures detailed in Table 1 were prepared in water and stirred for 7 days at room temperature. The solid products were isolated by vacuum filtration, washed with copious amounts of deionised water and a small amount of acetone, then dried in an oven for 4 hours at $40^{\circ} \mathrm{C}$.

Table 1: Summary of HDS synthesis conditions.

\begin{tabular}{ccc}
\hline HDS & Starting materials & Volume (mI) \\
\hline $\begin{array}{c}{\left[\mathrm{Zn}(\mathrm{OH})_{8}\right]\left(\mathrm{NO}_{3}\right)_{2} \cdot y \mathrm{H}_{2} \mathrm{O}} \\
{\left[\mathrm{Zn}-\mathrm{NO}_{3}\right]}\end{array}$ & $\mathrm{ZnO}(4.2 \mathrm{~g})+\mathrm{Zn}\left(\mathrm{NO}_{3}\right)_{2} \cdot 6 \mathrm{H}_{2} \mathrm{O}(24.1 \mathrm{~g})$ & 60 \\
{$\left[\mathrm{Zn} \mathrm{n}_{5}(\mathrm{OH})_{8}\right] \mathrm{Cl}_{2} \cdot y \mathrm{H}_{2} \mathrm{O}$} & $\mathrm{ZnO}(3.0 \mathrm{~g})$ and $\mathrm{ZnCl}{ }_{2}(7.26 \mathrm{~g})$ & 18 \\
{$[\mathrm{Zn}-\mathrm{Cl}]$} & $\mathrm{ZnO}(3.0 \mathrm{~g})+\mathrm{Ni}\left(\mathrm{NO}_{3}\right)_{2} \cdot 6 \mathrm{H}_{2} \mathrm{O}(8.73 \mathrm{~g})$ & 18 \\
{$\left[\mathrm{Zn}_{3} \mathrm{Ni}_{2}(\mathrm{OH})_{8}\right]\left(\mathrm{NO}_{3}\right)_{2} \cdot y \mathrm{H}_{2} \mathrm{O}$} & & \\
{$\left[\mathrm{NiZn}-\mathrm{NO}_{3}\right]$} & $\mathrm{ZnO}(3.0 \mathrm{~g})+\mathrm{Co}\left(\mathrm{NO}_{3}\right)_{2} \cdot 6 \mathrm{H}_{2} \mathrm{O}(8.73 \mathrm{~g})$ & 18 \\
{$\left[\mathrm{Zn}_{3.8} \mathrm{CO}_{1.2}(\mathrm{OH})_{8}\right]\left(\mathrm{NO}_{3}\right)_{2} \cdot y \mathrm{H}_{2} \mathrm{O}$} & & \\
{$\left[\mathrm{CoZn}-\mathrm{NO}_{3}\right]$} & & \\
\hline
\end{tabular}

\subsubsection{Intercalation reactions}

Intercalation was achieved by combining $0.4 \mathrm{mmol}$ of an HDS with a 4-fold excess of the guest anions. $10 \mathrm{ml}$ of deionised water was added to the solid materials, and the mixture stirred at $60^{\circ} \mathrm{C}$ for 3 days. The solid products were filtered under vacuum, washed with deionised water, and dried.

\subsubsection{Guest recovery}

The ability to recover the guest ions intact after intercalation was investigated in selected cases by reacting ca. $50 \mathrm{mg}$ of the intercalate with approximately $100 \mathrm{mg}$ of $\mathrm{Na}_{2} \mathrm{CO}_{3}$ in $\mathrm{D}_{2} \mathrm{O}$ overnight at $80{ }^{\circ} \mathrm{C}$. The resultant suspension was filtered and the filtrate analysed by ${ }^{1} \mathrm{H}$ NMR. 


\subsection{Characterisation}

\subsubsection{X-ray diffraction}

X-ray diffraction (XRD) was performed using a Philips PW1830 instrument operating at $40 \mathrm{kV}$ and 25 $\mathrm{mA}$ with $\mathrm{Cu} \mathrm{K} \alpha$ radiation $(\lambda=1.5418 \AA$ ). Samples were finely ground and mounted on aluminium plates for measurement. Patterns were recorded over the $2 \theta$ range from $2-20^{\circ}$. Diffracted intensity from the sample holder did not interfere with sample characterisation.

\subsubsection{IR spectroscopy}

IR spectra were recorded on a Perkin-Elmer Spectrum 100 instrument. Data were recorded from 4000 to $650 \mathrm{~cm}^{-1}$ at a resolution of $2 \mathrm{~cm}^{-1}$.

\subsubsection{NMR spectroscopy}

${ }^{1} \mathrm{H}$ NMR spectra were obtained on a Bruker Avance-400 instrument at ambient temperature $\left({ }^{1} \mathrm{H}\right.$ frequency: $400 \mathrm{MHz}$ ). Samples were dissolved in $\mathrm{D}_{2} \mathrm{O}$ prior to measurement.

\subsubsection{Elemental analysis}

$\mathrm{C}, \mathrm{H}$, and $\mathrm{N}$ contents were determined using the quantitative combustion technique on a Carlo Erba CE1108 elemental analyser.

\subsubsection{In situ X-ray diffraction}

The first series of in situ XRD measurements was performed on Beamline F3 of the DORIS synchrotron at the Deutsches Elektronen-Synchrotron (DESY), Hamburg, Germany. The energydispersive X-ray diffraction (EDXRD) technique was employed here. Further in situ XRD experiments were undertaken at the Diamond Light Source, using Beamline I12 and the Oxford-Diamond In Situ Cell (ODISC). These used an angle-dispersive modality, with an X-ray beam monochromated at $c a$. $0.23 \AA$ and a Pixium area detector. Full details of the equipment used is reported elsewhere. ${ }^{25,26}$

Both at DESY and Diamond, $0.4 \mathrm{mmol}$ of the desired HDS was mixed with $1.6 \mathrm{mmol}$ of the guest ion in $10 \mathrm{ml}$ of deionised water and heated to the desired temperature. Diffraction patterns were recorded every 60 seconds (DESY) or 4 seconds (Diamond) until no further changes in these were observed. Data analysis was performed by integrating reflections of interest using the F3Tool software (DESY), or by employing Fit2 $\mathrm{D}^{27}$ to convert the as-collected images into one-dimensional patterns, subtracting the background, and applying in-house tools to integrate the reflections of interest (Diamond). Integrated data were subsequently probed using the Avrami-Erofe'ev model; ${ }^{28-}$ ${ }^{31}$; more details are given in the results section. 


\subsubsection{Modelling}

Models of the $\mathrm{Zn}-\mathrm{NO}_{3}$ derived HDS systems were built in the space group $\mathrm{C} 2 / m$, using the structure previously reported by Stahlin and Oswald. ${ }^{32}$ In this symmetry, $\beta=93.28^{\circ}, a=19.48 \AA, b=6.238 \AA$ and $c=5.517 \AA$. All molecular dynamics (MD) simulations were carried out using the Materials Studio v5.5 software package (Accelrys Software Inc). ${ }^{33}$ Temperature and pressure control were implemented using the Andersen ${ }^{34}$ and the Berendsen ${ }^{35}$ methods respectively. Coulombic interactions were computed by the Ewald summation technique ${ }^{36}$ and van der Waals interactions using a "spline-cut off" method. The simulations were performed with the aid of the LDHFF force field. ${ }^{37}$ The time-step was set to be $1 \mathrm{fs}$, which is deemed to be suitable for the characterisation of thermal motion, ${ }^{38}$ and the simulation time at $5 \mathrm{~ns}$. For MD work, both water bound to tetrahedral $\mathrm{Zn}$ and free interlayer water were included in the simulation, with models of the final products isolated ex situ constructed using the formulae $\left[\mathrm{Zn}_{5}(\mathrm{OH})_{8}(\mathrm{Val})_{2} \cdot 3 \mathrm{H}_{2} \mathrm{O}\right]_{4},\left[\mathrm{Zn}_{5}(\mathrm{OH})_{8}(\mathrm{Nap})_{2} \cdot 3 \mathrm{H}_{2} \mathrm{O}\right]_{2}$ and $\left[\mathrm{Zn}_{5}(\mathrm{OH})_{8}(\mathrm{Dic})_{2} \cdot 4 \mathrm{H}_{2} \mathrm{O}\right]_{2}$. The interactions between the layers and free interlayer water are known to be small, and so the differences between the amounts of water observed experimentally and those approximated in this approach should not lead to the introduction of any significant errors. For MD work on the intermediate phases observed in situ, the same model as above was used for Dic. In the Nap case free water molecules caused the simulation to fail, and thus only water bound to tetrahedral $\mathrm{Zn}$ was included (formula: $\left[\mathrm{Zn}_{5}(\mathrm{OH})_{8}(\mathrm{Nap})_{2} \cdot 2 \mathrm{H}_{2} \mathrm{O}\right]_{2}$ )

\section{Results and Discussion}

\subsection{Intercalation into $\mathrm{CoZn}-\mathrm{NO}_{3}$}

It proved facile to intercalate the APIs into the $\mathrm{CoZn}-\mathrm{NO}_{3} \mathrm{HDS}$ through anion exchange. XRD patterns of the drug intercalates of $\mathrm{CoZn}-\mathrm{NO}_{3}$ are given in Figure 2. The reaction products show no characteristic basal reflections of the starting material, and a shift of the hoo basal reflections to lower angles; this corresponds to an increase in interlayer distance consistent with the incorporation of a larger anion (see Table 2). The interlayer spacings seen are in good agreement with previous results for LDHs: Khan et al. recorded d-spacings of $22.3 \AA$ for Dic, $21.5 \AA$ for Nap and $18.7 \AA$ for Val .${ }^{39}$ All the diffraction patterns illustrate peak broadening, indicative of stacking defects. 


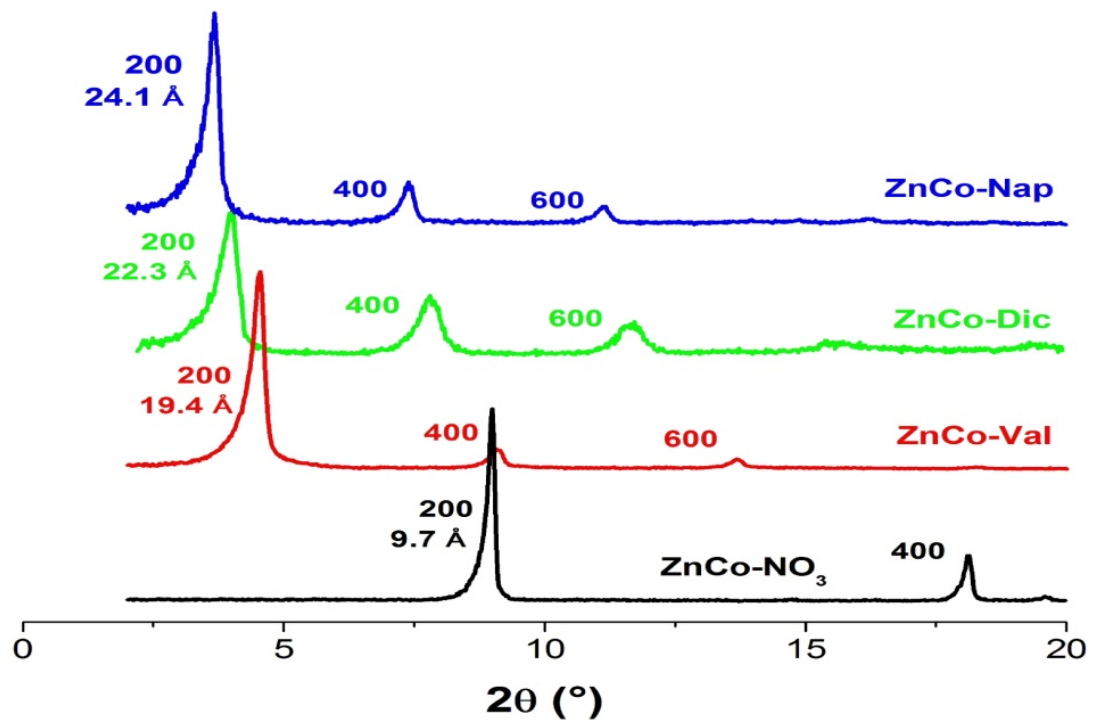

Figure 2: XRD patterns of $\mathrm{CoZn}-\mathrm{NO}_{3}$ and its intercalates.

Elemental analyses of the intercalation compounds (Table 2) indicated complete replacement of nitrate with the API guests had been achieved.

Table 2: Interlayer spacings and chemical formulae of the various HDS-drug composites prepared.

\begin{tabular}{|c|c|c|c|}
\hline ID & $d_{200}(\AA)$ & Formula & $\begin{array}{c}\text { Elemental analysis (\%) } \\
\text { Obsd (calcd) }\end{array}$ \\
\hline $\mathrm{CoZn}-\mathrm{NO}_{3}$ & 9.7 & {$\left[\mathrm{Co}_{1.2} \mathrm{Zn}_{3.8}(\mathrm{OH})_{8}\right]\left(\mathrm{NO}_{3}\right)_{2} \cdot 2 \mathrm{H}_{2} \mathrm{O}$} & - \\
\hline \multirow{3}{*}{ CoZn-Val } & \multirow{3}{*}{19.4} & \multirow{3}{*}[\mathrm{Co}_{1.2}\mathrm{Zn}_{3.8}(\mathrm{OH})_{8}]{$\left(\mathrm{C}_{8} \mathrm{H}_{15} \mathrm{O}_{2}\right)_{2} \cdot 2.5 \mathrm{H}_{2} \mathrm{O}$} & C $24.46(24.43)$ \\
\hline & & & H 5.55 (5.51) \\
\hline & & & N $0.0(0.0)$ \\
\hline \multirow{3}{*}{ CoZn-Dic } & \multirow{3}{*}{22.3} & \multirow{3}{*}[\mathrm{Co}_{1.2}\mathrm{Zn}_{3.8}(\mathrm{OH})_{8}]{$\left(\mathrm{C}_{14} \mathrm{H}_{10} \mathrm{Cl}_{2} \mathrm{NO}_{2}\right)_{1.6}\left(\mathrm{CO}_{3}\right)_{0.2} \cdot 2 \mathrm{H}_{2} \mathrm{O}$} & C $28.25(27.83)$ \\
\hline & & & H 2.77 (2.89) \\
\hline & & & N $1.44(2.30)$ \\
\hline \multirow{3}{*}{ CoZn-Nap } & \multirow{3}{*}{24.1} & \multirow{3}{*}[\mathrm{Co}_{1.2}\mathrm{Zn}_{3.8}(\mathrm{OH})_{8}]{$\left(\mathrm{C}_{14} \mathrm{H}_{13} \mathrm{O}_{3}\right)_{1.8}\left(\mathrm{CO}_{3}\right)_{0.1} \cdot 3.4 \mathrm{H}_{2} \mathrm{O}$} & C 32.21 (32.49) \\
\hline & & & H $4.12(4.12)$ \\
\hline & & & N $0.0(0.0)$ \\
\hline $\mathrm{NiZn}-\mathrm{NO}_{3}$ & 9.7 & $\mathrm{Ni}_{2} \mathrm{Zn}_{3}(\mathrm{OH})_{8}\left(\mathrm{NO}_{3}\right)_{2} \cdot 2 \mathrm{H}_{2} \mathrm{O}$ & - \\
\hline \multirow{3}{*}{ NiZn-Dic } & \multirow{3}{*}{$21.2 / 15.6^{\mathrm{a}}$} & \multirow{3}{*}[\mathrm{Ni}_{2}\mathrm{Zn}_{3}(\mathrm{OH})_{8}]{$\left(\mathrm{C}_{14} \mathrm{H}_{10} \mathrm{Cl}_{2} \mathrm{NO}_{2}\right)_{1.65}\left(\mathrm{NO}_{3}\right)_{0.35} \cdot 2 \mathrm{H}_{2} \mathrm{O}$} & C $27.91(27.90)$ \\
\hline & & & H $2.42(2.89)$ \\
\hline & & & N $3.31(2.82)$ \\
\hline \multirow{3}{*}{ NiZn-Nap } & \multirow{3}{*}{24.2} & \multirow{3}{*}[\mathrm{Ni}_{2}\mathrm{Zn}_{3}(\mathrm{OH})_{8}]{$\left(\mathrm{C}_{14} \mathrm{H}_{13} \mathrm{O}_{3}\right)_{1.72}\left(\mathrm{CO}_{3}\right)_{0.14} \cdot 2.7 \mathrm{H}_{2} \mathrm{O}$} & C $32.21(32.29)$ \\
\hline & & & H $4.03(4.00)$ \\
\hline & & & N $0.0(0.0)$ \\
\hline $\mathrm{Zn}-\mathrm{NO}_{3}$ & 9.7 & {$\left[\mathrm{Zn}_{5}(\mathrm{OH})_{8}\right]\left(\mathrm{NO}_{3}\right)_{2} \cdot 2 \mathrm{H}_{2} \mathrm{O}$} & - \\
\hline \multirow{3}{*}{ Zn-Dic } & \multirow{3}{*}{$22.3 / 19.5^{\mathrm{a}}$} & \multirow{3}{*}[\mathrm{Zn}_{5}(\mathrm{OH})_{8}]{$\left(\mathrm{C}_{14} \mathrm{H}_{10} \mathrm{Cl}_{2} \mathrm{NO}_{2}\right)_{2}\left(\mathrm{C}_{14} \mathrm{H}_{11} \mathrm{Cl}_{2} \mathrm{NO}_{2}\right)_{0.4} \cdot 2 \mathrm{H}_{2} \mathrm{O}$} & C $33.68(33.42)$ \\
\hline & & & H 1.67 (3.01) \\
\hline & & & N 3.05 (2.78) \\
\hline \multirow{3}{*}{ Zn-Nap } & \multirow{3}{*}{$23.6 / 20.3^{a}$} & \multirow{3}{*}[\mathrm{Zn}_{5}(\mathrm{OH})_{8}]{$\left(\mathrm{C}_{14} \mathrm{H}_{13} \mathrm{O}_{3}\right)_{2} \cdot 2 \mathrm{H}_{2} \mathrm{O}$} & C 34.87 (35.12) \\
\hline & & & H $3.90(4.00)$ \\
\hline & & & N $0.0(0.0)$ \\
\hline
\end{tabular}

The intercalation compounds were also characterised by IR spectroscopy (see Figure 3). The spectrum of CoZn- $\mathrm{NO}_{3}$ shows typical features of an HDS. A broad peak centred at around $3250 \mathrm{~cm}^{-1}$ 
corresponds to $\mathrm{H}$-bonded $\mathrm{OH}$ groups of the HDS layers. The $\delta$-vibration of the interlayer water molecules is located at $1636 \mathrm{~cm}^{-1}$, the $\mathrm{NO}_{3}^{-}$vibrations at $c a .1373 \mathrm{~cm}^{-1}$, and $\mathrm{Zn}-\mathrm{O}$ vibrations from the HDS layers are visible below $1000 \mathrm{~cm}^{-1}$. The spectrum of Dic (Figure 3 ) displays distinctive symmetric and asymmetric carboxylate bands at 1397 and $1572 \mathrm{~cm}^{-1}$ respectively. An additional peak at 746 $\mathrm{cm}^{-1}$ corresponds to the C-Cl group. The IR spectrum from the CoZn-Dic intercalation compound is a combination of those from the HDS and API, containing a broad $\mathrm{OH}$ absorption band at around 3400 $\mathrm{cm}^{-1}$, distinctive carboxylate vibrations at 1580 and $1397 \mathrm{~cm}^{-1}$, and a C-Cl vibration at $746 \mathrm{~cm}^{-1}$. There is no visible peak at $1373 \mathrm{~cm}^{-1}$ for the intercalate, implying that the nitrate ions have been displaced from the structure. The shift in the position of the asymmetric carboxylate band from $1572 \mathrm{~cm}^{-1}$ in Dic to $1580 \mathrm{~cm}^{-1}$ in CoZn-Dic may be attributed to electrostatic interactions between the COOgroups of the anions and the hydroxide layers.

The IR spectra for the other $\mathrm{CoZn}-\mathrm{NO}_{3}$ intercalates also show the disappearance of the nitrate absorption and the presence of characteristic bands from the guest ions (see Supplementary Information, Figure S1).

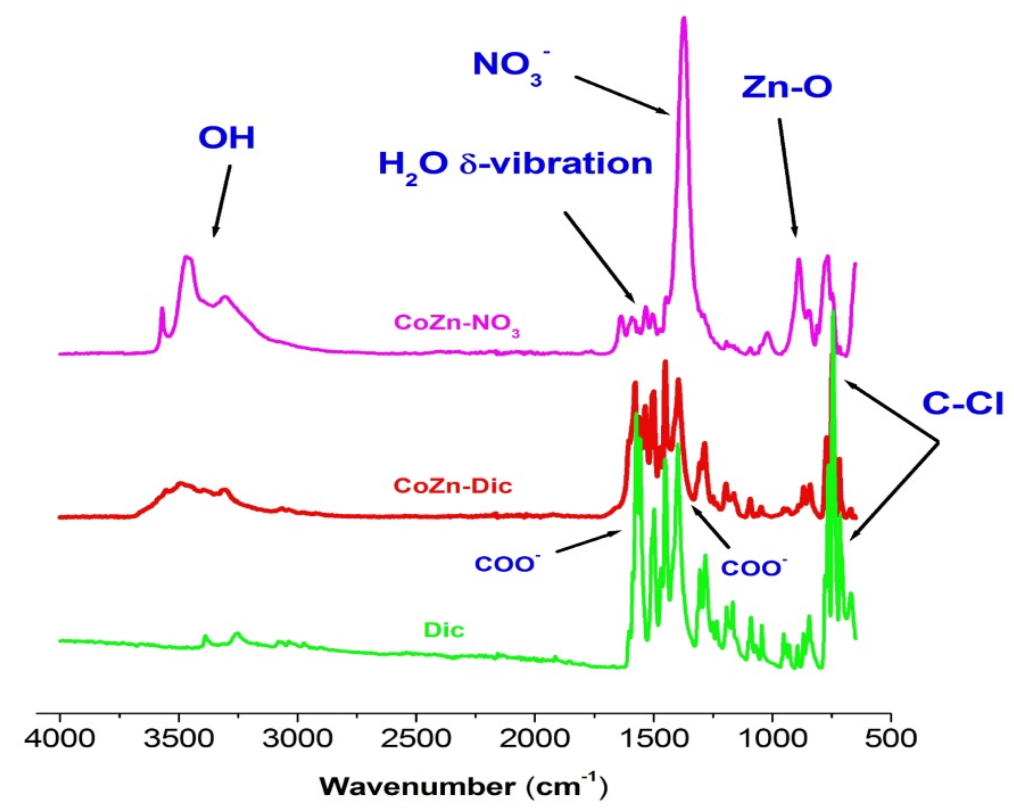

Figure 3: IR spectra of CoZn-NO $\mathrm{NO}_{3}$ CoZn-Dic and Dic.

\subsection{Intercalation into other HDSs}

Intercalation into two further $\mathrm{HDSs}, \mathrm{Zn}-\mathrm{NO}_{3}$ and $\mathrm{NiZn}-\mathrm{NO}_{3}$, was also explored. Attempts to react Val with $\mathrm{Zn}-\mathrm{NO}_{3}$ were unsuccessful, yielding $\mathrm{ZnO}$ as the solid reaction product (see Figure S2). For the other materials, the XRD and elemental analysis data (Table 2 and Figure S2) show the intercalation compounds to be largely analogous to those prepared from $\mathrm{CoZn}-\mathrm{NO}_{3}$. In the diffraction patterns of Zn-Dic, NiZn-Dic and the Zn-Nap material it appears that there are two intercalate phases with 
different $d$-spacings (see Figure S2 and Table 2). These may be ascribed to two different orientations of the guest ions. IR spectroscopy (Figure S3) additionally demonstrated successful intercalation of the Dic and Nap anions into all the HDSs.

\subsection{Guest recovery}

The CoZn-Dic, CoZn-Nap and CoZn-Val intercalates were reacted with $\mathrm{Na}_{2} \mathrm{CO}_{3}$ in $\mathrm{D}_{2} \mathrm{O}$, and NMR spectra recorded of the filtrates from these reactions. The spectra after deintercalation are observed to be identical to those of solutions of the pure APIs, confirming that the structural integrity of these drug molecules is retained. Exemplar data are given in Figure S4.

\subsection{Guest orientation}

Molecular dynamics (MD) simulations were performed to explore the orientations of the guests in the interlayer space. These were performed using the reported structure for $\mathrm{Zn}-\mathrm{NO}_{3}{ }^{32}$ since no crystal structures are known for the mixed-metal systems. For Val, simulations indicate a bilayer of ions is formed between the layers, as shown in Figure 4(a). The model gives an interlayer spacing of $19.1 \pm 0.1 \AA$. This result is in good agreement with the experimental value (19.4 ̊), with the small difference between experimental and simulation being well within the range of deviations reported in previous LDH modelling studies (very little modelling work has been done using HDSs). ${ }^{40-44}$ The Val ions adopt a perpendicular position in the interlayer regions, with their carboxylate groups facing the HDS layer and the aliphatic chains towards the centre. The simulation shows that $\mathrm{H}$-bonding occurs between the $\mathrm{COO}^{-}$group of Val, water and the HDS layer.

Simulations with Nap ions also suggest a bilayer arrangement of guests between the HDS layers, with a $d$-spacing of $24.0 \pm 0.1 \AA$ (Figure $4(\mathrm{~b})$ ), in very good agreement with the experimental value of 23.6 - $24.2 \AA$ seen for the major intercalate phase (for Zn-Nap, a second API-loaded phase with a lower $\mathrm{d}$-spacing was observed). The Nap ions form an " $\mathrm{X}$ " shape in three dimensions. This keeps the hydrophobic regions of the molecules close together in the centre of the interlayer, and the hydrophilic regions close to the tetrahedral $\mathrm{Zn}^{2+}$ and facing the positively charged layers. Dic ions are similarly predicted to form an " $X$ " shape (Figure 4(c)), leading to a simulated interlayer spacing of $22.0 \pm 0.3 \AA$ (cf. $21.2-22.3 \AA$ observed experimentally). H-bonds are also calculated to be present in the Nap and Dic MD simulations. 


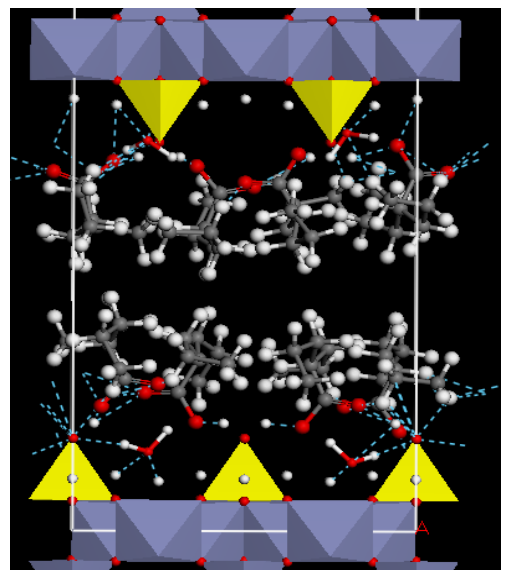

(a)

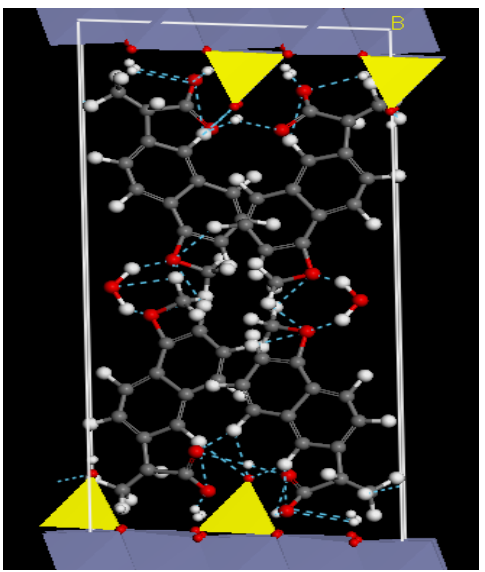

(b)

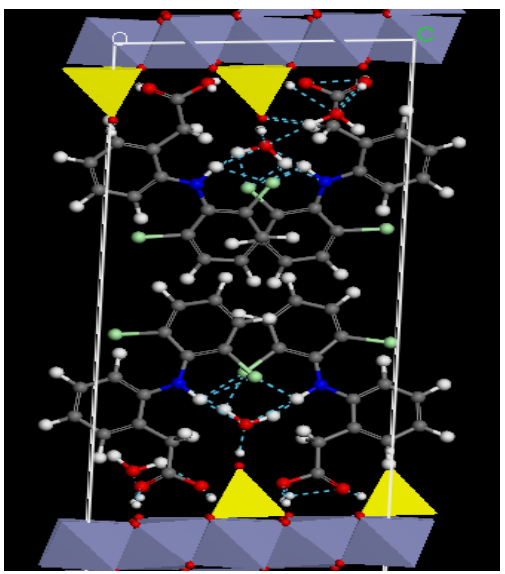

(c)

Figure 4: MD results (a) Val; (b) Nap; and, (c) Dic. H-Bonds are shown in blue and the tetrahedral $\mathrm{Zn}^{2+}$ sites are highlighted in yellow.

\subsection{In situ diffraction}

\subsubsection{Intercalation of Val}

Data for $\mathrm{CoZn}-\mathrm{NO}_{3}$ are given in Figure $5(\mathrm{a})$. The reaction at $80{ }^{\circ} \mathrm{C}$ was seen to be a one stage process, proceeding directly from the starting material to the product. The intercalate exhibits virtually the same d-spacing in situ (19.8) as seen in laboratory syntheses (19.4 Å). No crystalline intermediate phases were visible in the diffraction data.

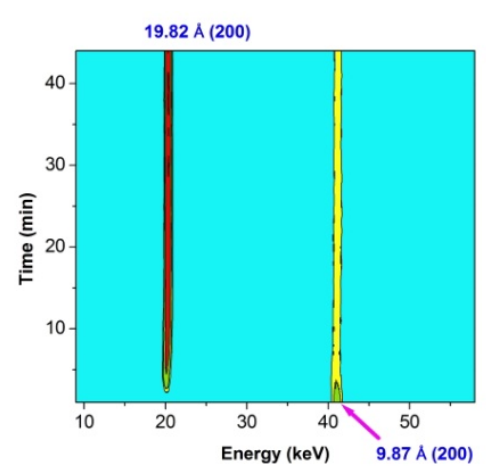

(a)

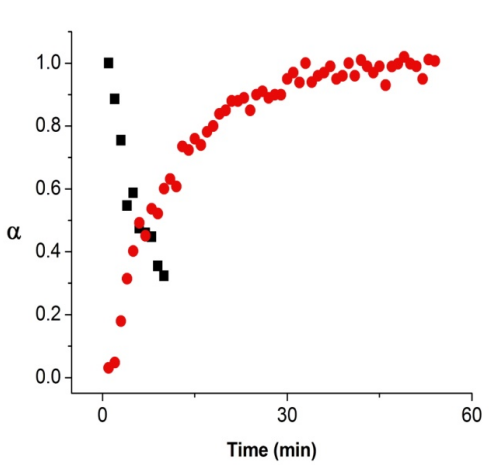

(b)

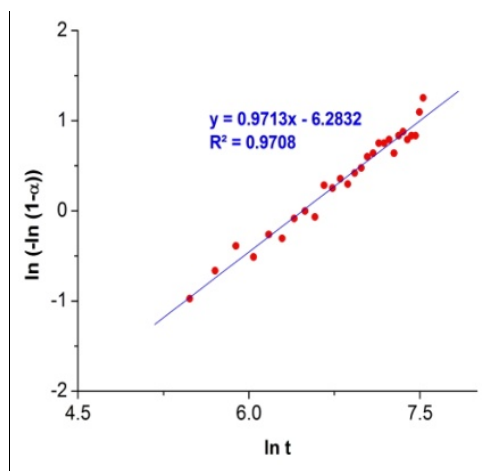

(c)

Figure 5: In situ XRD data for the intercalation of Val into $\mathrm{CoZn}-\mathrm{NO}_{3}$ at $80{ }^{\circ} \mathrm{C}$. (a) Contour plot of the raw data; (b) extent of reaction vs. time data showing the changes in intensity of the host ( $\square$ ) and product (O) 200 reflections; and, (c) a Sharp-Hancock plot for the product 200 reflection.

The intensities of the 200 reflections of the $\mathrm{CoZn}-\mathrm{NO}_{3}$ and $\mathrm{CoZn}$-Val materials were integrated, and converted into extent of reaction, $\alpha$. This is essentially a normalisation processes: $\alpha=I_{\text {hkl }}(t) / I_{\text {hkl }}(\max )$, where $I_{h k l}(t)$ is the intensity of a reflection $h k l$ at time $t$, and $I_{h k l}(\max )$ is the maximum intensity of that reflection. A plot of $\alpha$ vs. time is illustrated in Figure $5(b)$. The curves of the starting material and product cross at $\alpha \approx 0.45$, which indicates a one stage transformation. This crossing point shows that the diffracted intensity lost from the starting material is matched by intensity gained by the product, and therefore the intercalation reaction has not passed through an intermediate phases (if there were an intermediate stage, the starting material and product curves should cross close to $\alpha \approx 0$ ). 
The Avrami-Erofe'ev model, which has been very widely used with intercalation processes, ${ }^{45-47}$ was applied to the data for Val intercalation. This states:

$$
\alpha=1-\mathrm{e}^{(\mathrm{kt})^{\mathrm{n}}}
$$

where $\alpha$ is the extent of reaction, $t$ is the time, $k$ the rate constant, and $n$ an exponent which can be used to infer details of the reaction mechanism. ${ }^{10}$ A Sharp-Hancock plot of $\ln (-\ln (1-\alpha))$ vs. In $t$ can be conveniently used to calculate $\mathrm{n}$ and $\mathrm{k}$ (Figure $5(\mathrm{c})$ ). The plot in Figure $5(\mathrm{c})$ is linear, indicating that the reaction proceeds via a consistent mechanism over almost the entire course of the reaction, and that the Avrami-Erofe'ev model is suitable to describe this system. The reaction exponent $n$ is observed to be ca. 1 (Table 3). This suggests that the reaction is a nucleation growth process, with instantaneous nucleation followed by two dimensional diffusion control. The layer edges are the nucleation sites, and "instantaneous" nucleation suggests that all these are saturated with guest ions at the start of the reaction. Two-dimensional diffusion control indicates that, once a pair of layers has been prised apart, the movement of the new guest ions into the interlayer space is facile: thus, diffusion control operates thereafter. ${ }^{10}$

Table 3: The results of Avrami-Erofe'ev analyses of the intercalation processes.

\begin{tabular}{|c|c|c|c|c|}
\hline ID & $\mathrm{T} /{ }^{\circ} \mathrm{C}$ & $\mathbf{n}$ & $k\left(10^{-3} \mathrm{~s}^{-1}\right)$ & Notes \\
\hline CoZn-Val & 80 & 1.04 & 2.96 & \\
\hline CoZn-Dic & 80 & \multicolumn{3}{|c|}{ Avrami-Erofe'ev kinetics not applicable } \\
\hline \multirow{2}{*}{ NiZn-Dic } & 75 & 1.01 & 1.03 & \multirow{2}{*}{$\mathrm{Ea} \approx 28.7 \mathrm{~kJ} \mathrm{~mol}^{-1}$} \\
\hline & 80 & 1.00 & 1.18 & \\
\hline Zn-Dic & 80 & \multicolumn{3}{|c|}{ Avrami-Erofe'ev kinetics not applicable } \\
\hline CoZn-Nap & 80 & \multicolumn{3}{|c|}{ Avrami-Erofe'ev kinetics not applicable } \\
\hline \multirow{4}{*}{ NiZn-Nap } & 60 & 0.98 & 1.22 & \multirow{3}{*}{$\mathrm{Ea} \approx 33.4 \mathrm{~kJ} \mathrm{~mol}^{-1}$} \\
\hline & 70 & 0.98 & 1.63 & \\
\hline & 75 & 1.19 & 2.09 & \\
\hline & 80 & \multicolumn{3}{|c|}{ Avrami-Erofe'ev kinetics not applicable } \\
\hline Zn-Nap & 80 & \multicolumn{3}{|c|}{ Avrami-Erofe'ev kinetics not applicable } \\
\hline
\end{tabular}

\subsubsection{Intercalation of Dic}

This reaction was studied at $80{ }^{\circ} \mathrm{C}$ for all three HDSs. Plots of the raw data obtained on DESY are depicted in Figure 6. 


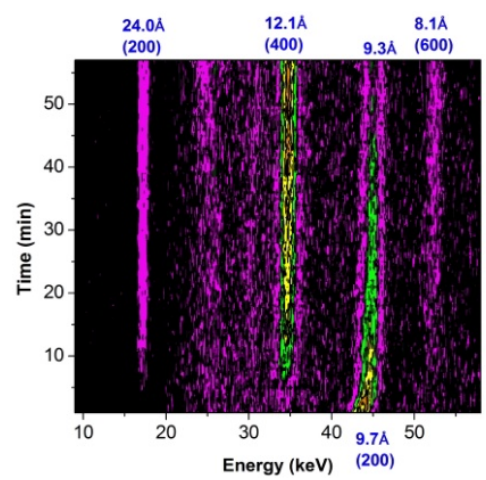

(a)

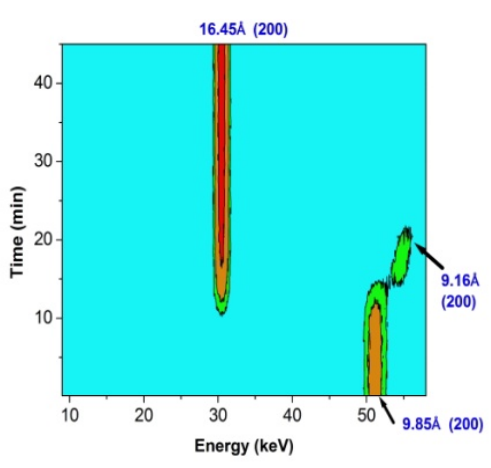

(b)

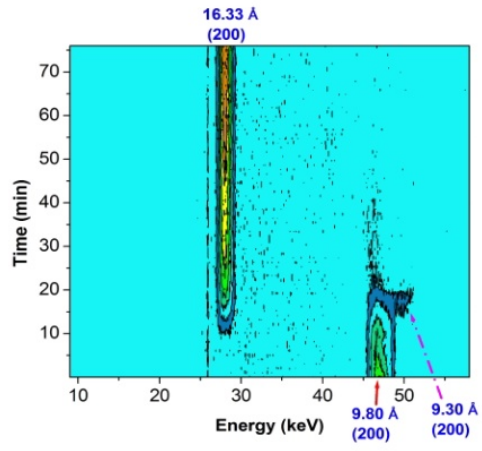

(c)

Figure 6: Plots of the raw data for intercalation of Dic into (a) $\mathrm{NiZn}-\mathrm{NO}_{3}$; (b) $\mathrm{CoZn}-\mathrm{NO}_{3}$; and, (c) $\mathrm{Zn}-\mathrm{NO}_{3}$ at $80{ }^{\circ} \mathrm{C}$.

Dic intercalation into NiZn- $\mathrm{NO}_{3}$ appears to be a straightforward process: the reaction proceeds directly from the starting material to the product, which at $24.3 \AA$ has a $d$-spacing somewhat higher that observed in laboratory synthesis (presumably due to increased hydration levels). This is confirmed by the $\alpha$ vs. time plots of host and product crossing at ca. 0.5 (Figure S5(a)). An AvramiErofe'ev analysis yields $\mathrm{n} \approx 1$ (Figure S5(b)), indicating a mechanism of 2D diffusion control following instantaneous nucleation as discussed above. Performing the reaction at two different temperatures allowed the activation energy to be estimated at ca. $28.7 \mathrm{~kJ} \mathrm{~mol}^{-1}$.

The CoZn- $-\mathrm{NO}_{3}$ and $\mathrm{Zn}-\mathrm{NO}_{3}$ data are more complex. The d-spacing of the final product in the in situ experiments is $16.3-16.5 \AA$, much lower than the $22.3 \AA$ observed ex situ. Further, in both Figure $6(b)$ and (c), a reflection at around $9.16-9.30 \AA$ is observed to grow in at the same time as the product first appears. This was initially thought to be an artefact, and to verify this hypothesis further experiments were performed with $\mathrm{Zn}-\mathrm{NO}_{3}$ on Beamline 112 of the Diamond Light Source, which has much better resolution. The resultant data are given in Figure S6: they verify those obtained on DESY, clearly showing the reflection at ca. $9.2 \AA$ to be genuine and not an experimental artefact. MD simulations were carried out to model this phase and predicted a system with Dic ions intercalated in a horizontal arrangement. This gave a d-spacing of $9.28 \AA$, close to the experimental value. Thus, it seems that at the start of the intercalation process some of the Dic ions intercalate vertically between the layers, while others intercalate horizontally and subsequently rearrange themselves.

To understand why the final product seen in situ has a 200 reflection with a lower $d$-spacing than observed ex situ, the reaction was run at $80{ }^{\circ} \mathrm{C}$ and the solid recovered by rapid filtration after 80 min. The XRD pattern of the quenched product (Figure S7) shows a virtually identical interlayer spacing to that observed in situ (15.6 ̊). The quenched product was returned to the Dic solution and left to stir at $80{ }^{\circ} \mathrm{C}$ for approximately $10 \mathrm{~h}$ further. The XRD pattern of the material recovered shows 
a very intense reflection at $20.5 \AA$, while the phase at $15.6 \AA$ has almost vanished. Thus, we can conclude that the $16.3 \AA$ phase seen in situ is a long-lived intermediate en route to the final product $\left(d_{200}=19.5-22.5 \AA\right)$. CHN analysis of the material recovered after 80 min shows that only $65 \%$ of the initial $\mathrm{NO}_{3}{ }^{-}$ions had been replaced; further reaction leads to replacement of the remaining ions to yield a fully intercalated product with a higher d-spacing (Table 2). MD simulations (Figure S8) indicated that the $15.6 \AA$ phase this contains the guest ions arranged in a perpendicular monolayer. The Dic carboxylate groups are close to the tetrahedral $\mathrm{Zn}^{2+}$ ions. This arrangement is thought to become unstable when the number of Dic ions in the interlayer region increases and the amount of $\mathrm{NO}_{3}{ }^{-}$ions declines. As a result, at a critical Dic content the ions rearrange themselves to give a phase with an interlayer spacing of $19.5-22.5 \AA$.

During the intercalation of Dic into $\mathrm{Zn}-\mathrm{NO}_{3}$ and $\mathrm{CoZn}-\mathrm{NO}_{3}$, we observed an initial drop in the intensity of the starting material 200 reflection, followed by a subsequent increase. This was observed in four independent experiments, both at Diamond (Figure S7) and DESY, and thus is believed to be a genuine feature of the reaction rather than an artefact arising from, for instance, a failure in stirring. We thus postulated that an additional intermediate phase might be forming, with a d-spacing very similar to that of the starting material.

To confirm this suggestion, experiments were performed with the HDS $\left[\mathrm{Zn}_{5}(\mathrm{OH})_{8}\right] \mathrm{Cl}_{2} \cdot y \mathrm{H}_{2} \mathrm{O}(\mathrm{Zn}-\mathrm{Cl})$ which has a different initial interlayer spacing $(7.8 \AA)$ but otherwise behaves similarly to $\mathrm{Zn}-\mathrm{NO}_{3}$. Quenching reactions were conducted under the same conditions as used for in situ studies, and the results are shown in Figure S9. The XRD patterns show clear reflections at 9.3 and $9.9 \AA$, suggesting that the in situ phenomenon seen during the intercalation of Dic into $\mathrm{Zn}-\mathrm{NO}_{3}$ is caused by an intermediate that has a d-spacing of $9.8 \AA$.

Plots of $\alpha$ vs. time for Dic intercalation into $\mathrm{CoZn}-\mathrm{NO}_{3}$ and $\mathrm{Zn}-\mathrm{NO}_{3}$ are depicted in Figure S10. Although it appears at first sight that the curves from the starting material and the $16 \AA$ intercalate cross at around $\alpha=0.5$, the situation is in fact more complex because of the presence of an intermediate with identical $d$-spacing to the starting material. Attempts were made to fit the Avrami-Erofe'ev model to the data, but these were inconclusive: the resultant Sharp-Hancock plots were decidedly non-linear, indicating a complex reaction which does not proceed via a consistent mechanism throughout. This is perhaps not surprising given the number of different phases identified on the reaction coordinate.

\subsubsection{Intercalation of Nap}


In situ diffraction data for the intercalation of Nap are given in Figure 7.

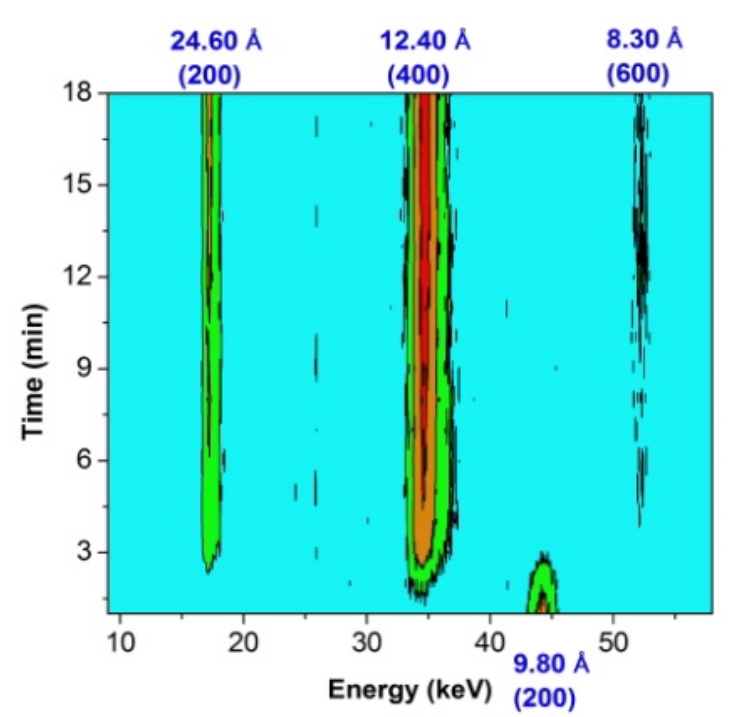

(a)

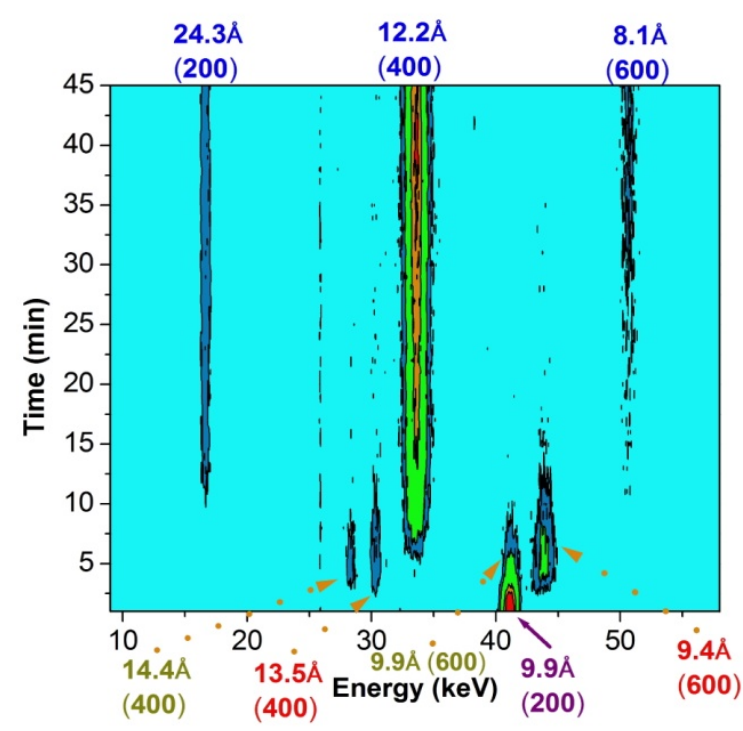

(b)

Figure 7: Plots of the raw data for intercalation of Nap into (a) NiZn- $-\mathrm{NO}_{3}$; and, (b) $\mathrm{CoZn}-\mathrm{NO}_{3}$ at $80^{\circ} \mathrm{C}$.

As for Dic, the process of Nap intercalation into $\mathrm{NiZn}-\mathrm{NO}_{3}$ is found to be a simple one-step process going directly from the starting material to the product. The host and product $\alpha$ vs. time curves cross at $\alpha \approx 0.5$ (see Figure S11). The product 200 reflection arises at around $24.6 \AA$ (400: $12.4 \AA$, 600: 8.3 $\AA$ ). The interlayer spacing observed in situ is thus very similar to that seen ex situ ( $24.2 \AA$ ). At $80^{\circ} \mathrm{C}$, the reaction appears not to follow Avrami kinetics, with highly non-linear Sharp-Hancock plots being seen. At lower temperatures, the reaction is again observed to proceed directly to the product, but linear Sharp-Hancock plots are produced and values for $n$ and $k$ may be extracted (Table 3). $n$ is found to be $c a$. 1 , indicative of 2D diffusion control following instantaneous nucleation as observed previously. The Arrhenius equation was used to estimate the kinetic energy; this was found to be approximately $33.4 \mathrm{~kJ} \mathrm{~mol}^{-1}$, consistent with a nucleation-controlled reaction.

The intercalation of Nap into $\mathrm{CoZn}-\mathrm{NO}_{3}$ at $80{ }^{\circ} \mathrm{C}$ (Figure $\left.7(\mathrm{~b})\right)$ shows that the final product observed in situ has essentially the same interlayer spacing as seen ex situ ( $24.3 \AA$ vs. $24.1 \AA ̊$ ). Clear crystalline intermediate phases are visible in the diffraction data, with three distinctive reflections that appear and disappear synchronously. These are believed to be the $400(14.4$ / $13.5 \AA$ ) and 600 (9.4 $\AA$ ) reflections of two higher d-spacing intermediate phases (the 200 positions of these at $27-29 \AA$ placed them beyond the detection window). Repeating these experiments on Beamline 112 at Diamond (Figure S12) identified the same features, with some additional reflections corresponding to these intermediate phases resolvable in the patterns. $\alpha$ vs $t$ curves for this system are given in Figure 8. The reflections from $\mathrm{CoZn}-\mathrm{NO}_{3}$ and CoZn-Nap cross at $\alpha \approx 0$, consistent with the observation of an intermediate. The starting material vs intermediate curves cross at $\alpha \approx 0.5$, as do 
the intermediate vs product curves. This indicates a two stage transformation. The results of MD simulations are presented in Figure S13. The higher d-spacing phases are found to arise from the Nap ions being arranged in a perpendicular bilayer, with a d-spacing of $28.0 \AA$. This arrangement is presumably unstable, and thus as the reaction continues the Nap ions rearrange themselves to give a phase with an interlayer spacing of $24.3 \AA$.

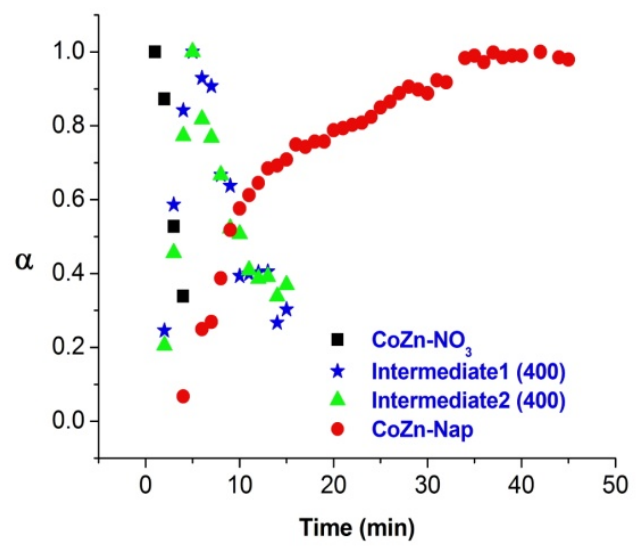

Figure 8: $\alpha$ vs. time plot for the intercalation of Nap into $\mathrm{CoZn}-\mathrm{NO}_{3}$ at $80{ }^{\circ} \mathrm{C}$. Intermediate 1 refers to the 400 reflection at $14.4 \AA$ and intermediate 2 to that at $13.5 \AA$.

The Sharp-Hancock plot for CoZn-Nap formation was decidedly non-linear, indicating that simple Avrami kinetics are not sophisticated enough to describe this complex system.

The intercalation of Nap into $\mathrm{Zn}-\mathrm{NO}_{3}$ produces two product phases of different d-spacings in the laboratory syntheses. This same phenomenon is seen in the time-resolved data (Figure 9). A phase first grows in at $20.8 \AA$ before a second product phase appears at $24.0 \AA$. These d-spacings are very similar to those seen ex situ (Table 2). Plotting the extent of reaction vs. time (Figure S14) suggests that the $20.8 \AA$ phase exists in equilibrium with the $24.0 \AA$ phase; although the integrated intensity of the former declines very slightly during the course of intercalation, it then appears to level off. There is a very transient and poorly crystalline intermediate phase which forms at $9.2 \AA$. This phase is believed on the basis of MD simulations to have the Nap ions intercalated horizontally, analogous to the Dic system discussed above. The data obtained on Diamond (Figure 9(b)) also show another, very poorly crystalline, intermediate phase present with a 002 reflection at $21.5 \AA$. 


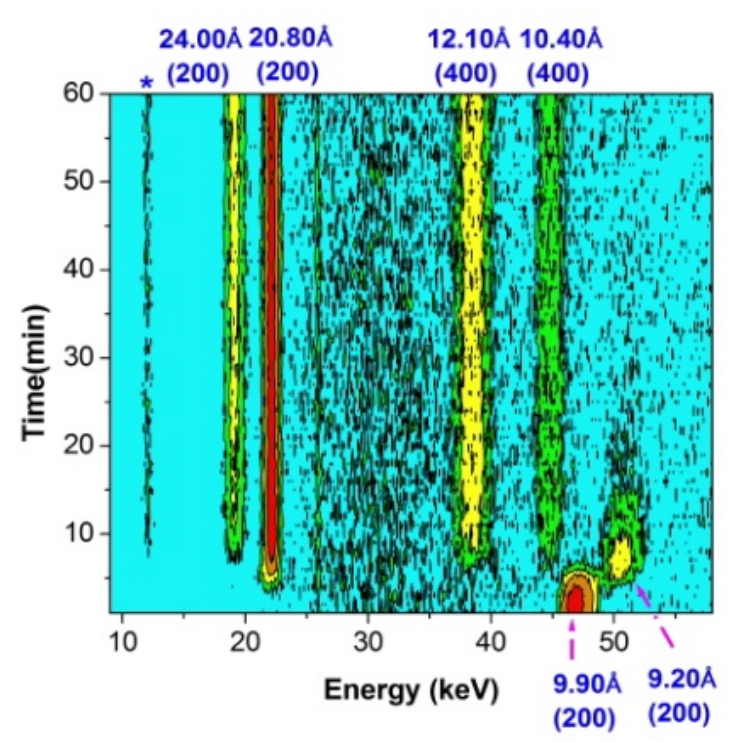

(a)

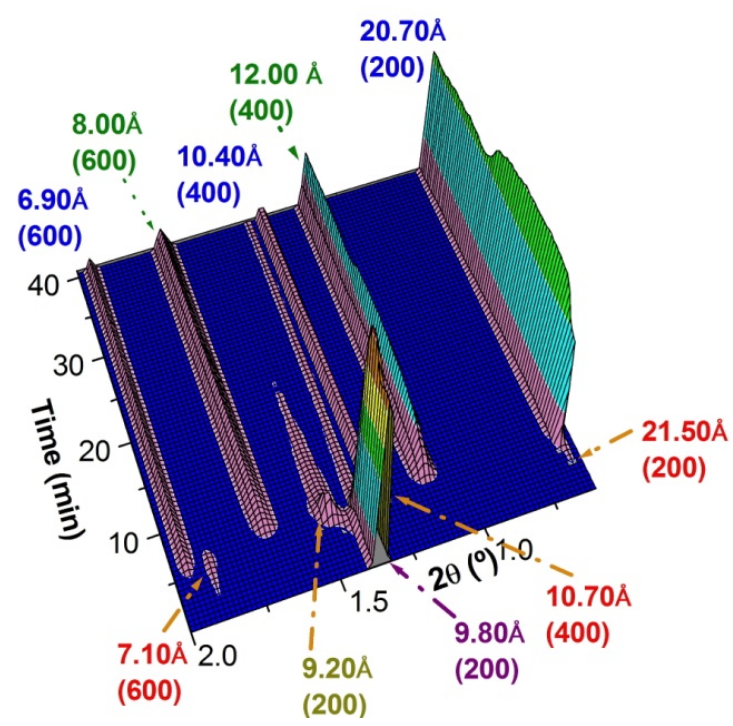

(b)

Figure 9: Time resolved XRD data obtained for the intercalation of Nap into $\mathrm{Zn}-\mathrm{NO}_{3}$ on (a) DESY and (b) Diamond at $80{ }^{\circ} \mathrm{C}$, showing the possible presence of a transient and low crystallinity intermediate phases (labelled in red/orange). The peak marked * is an escape peak from the Ge detector.

The Sharp-Hancock plot for the $24.0 \AA$ A product was non-linear, indicating the non-applicability of Avrami kinetics here. The $20.8 \AA$ phase produced a linear plot but the exponent value was not consistent with any of the possible mechanisms of reaction, and thus again it is thought Avrami kinetics cannot be applied. The simulated structure of the $24.0 \AA$ phase is discussed above; the other phases at 20.8 and $21.5 \AA$ are believed to be similar, but with reduced hydration levels.

\subsection{Drug release}

A drug release study was carried out on selected systems in phosphate buffered saline (PBS; pH 7.4) to explore the potential of the HDS systems for drug delivery. Dic release (see Figure 10(a)) was faster from $\mathrm{Zn}-\mathrm{NO}_{3}$ than from the HDSs containing a mixture of divalent metals ( $\mathrm{CoZn}-\mathrm{NO}_{3}$ and NiZn$\mathrm{NO}_{3}$ ). The drug was released fully within $6 \mathrm{~h}$ from $\mathrm{Zn}$-Dic, while a maximum of around $75 \%$ release was observed from NiZn-Dic after this time, and only $85 \%$ release was reached after $24 \mathrm{~h}$ (Figure 10(a)). Release from all the HDSs is initially rapid, followed by a slower and more sustained release phase. This two-stage release behaviour has previously been reported from LDH and HDS systems with various drugs, including NSAIDs. ${ }^{48-52}$ Similar Dic release profiles have been seen for both HDSs and LDHs. ${ }^{50,53,54}$ The metal composition of the layers clearly has an influence on the release rates obtained.

The Nap release profile from CoZn-Nap is given in Figure 10(b); the full drug loading was released within $5 \mathrm{~h}$. Nap is thus released more rapidly than Dic from the CoZn system, which could be 
explained by the higher solubility of the former. ${ }^{55,56}$ The release profiles seen here are more sustained than those previously observed. LDHs in general have been shown to release their drug cargo more quickly than HDSs and here Nap release proceeds more slowly than has been reported from both LDHs and HDSs, where complete release in less than 100 min was seen. ${ }^{20,57-59}$

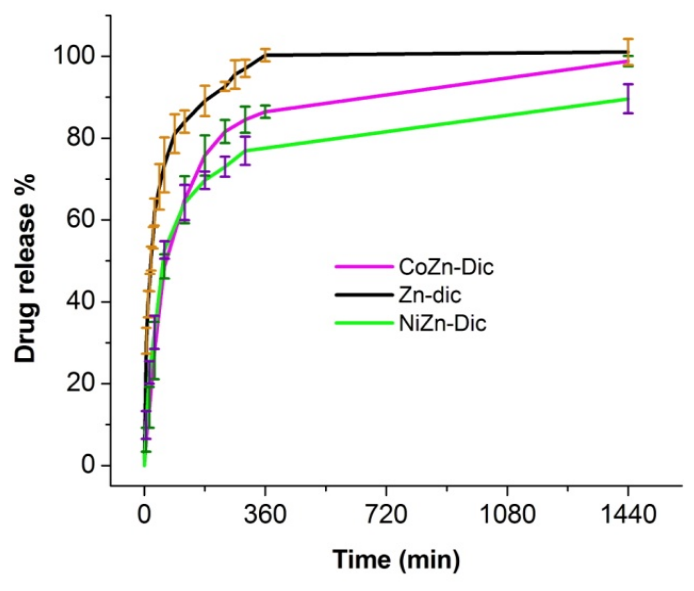

(a)

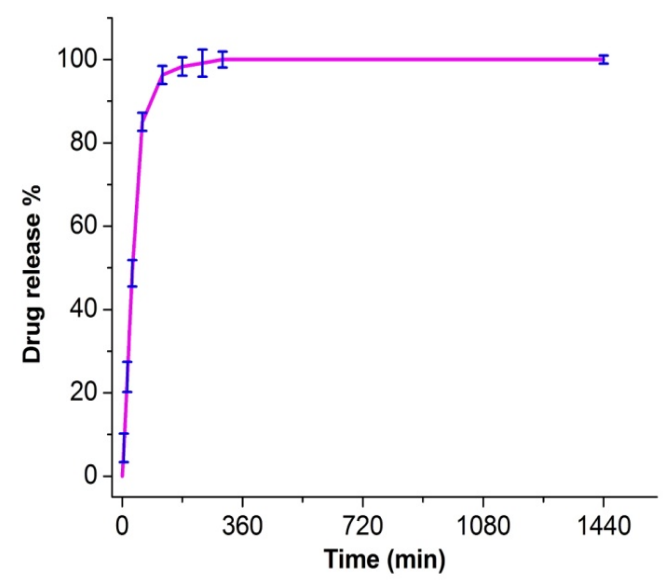

(b)

Figure 10: In vitro release of (a) Dic from Zn-Dic, NiZn-Dic and CoZn-Dic; (b) Nap from CoZn-Nap.

Trial release experiments were also carried out in conditions that mimic passage through the human gastrointestinal tract ( $2 \mathrm{~h}$ in a pH 1 medium, followed by transfer to a pH 6.8 PBS; see Figure S15). ZnDic released only $2 \%$ of its drug loading in the acidic media, but upon raising the $\mathrm{pH}$ to 6.8 this process was accelerated and most of the drug loading freed within $9 \mathrm{~h}$. Release from CoZn-Dic was slower, and was complete after around $21 \mathrm{~h}$. Again, very little release was seen at $\mathrm{pH} 1$. Release from both $\mathrm{Zn}$-Dic and CoZn-Dic was slower at pH 6.8 than 7.4; such a positive correlation between the rate of release from layered systems and $\mathrm{pH}$ has been reported previously. ${ }^{60,61}$ On the basis of the data reported herein, HDSs seem to have promise for sustained release. Further, the release profiles observed suggest that loading the drug-loaded HDSs into capsules would give formulations meeting the pharmacopeia requirements for intestinal drug targeting. ${ }^{62-64}$

\section{Conclusions}

The anions of diclofenac (Dic), naproxen (Nap), and valproic acid (Val) were intercalated into several $\mathrm{Zn}$-based hydroxy double salts (HDSs). The attempted intercalation of Val into $\left[\mathrm{Zn}_{5}(\mathrm{OH})_{8}\right]\left(\mathrm{NO}_{3}\right)_{2} \cdot 2 \mathrm{H}_{2} \mathrm{O}$ $\left(\mathrm{Zn}-\mathrm{NO}_{3}\right)$ led to the destruction of the HDS layers to yield $\mathrm{ZnO}$. In contrast, the presence of $\mathrm{Co}^{2+}$ in the HDS appears to stabilise the layers and resulted in the successful intercalation of Val into $\left[\mathrm{CO}_{1.2} \mathrm{Zn}_{3.2}(\mathrm{OH})_{8}\right]\left(\mathrm{NO}_{3}\right)_{2} \cdot 2 \mathrm{H}_{2} \mathrm{O}\left(\mathrm{CoZn}-\mathrm{NO}_{3}\right)$. Molecular dynamics simulations suggested that the Dic and Nap ions were arranged in an " $\mathrm{X}$ " shape, forming a bilayer arrangement in the interlayer space. Val 
was determined to adopt a position with its aliphatic groups parallel to the HDS layer, and again form a bilayer.

In situ time resolved X-ray diffraction experiments showed that the intercalation of Dic and Nap into $\mathrm{CoZn}-\mathrm{NO}_{3}$ and $\mathrm{Zn}-\mathrm{NO}_{3}$ proceeds by distinct intermediates, while their intercalation into $\mathrm{NiZn}-\mathrm{NO}_{3}$ are simple one step reactions proceeding directly from the starting material to product. The one-step processes obeyed simple Avrami-type kinetics and were found to be nucleation-governed processes, with instantaneous nucleation followed by 2D diffusion control. In contrast, where intermediates were observed Avrami kinetics could not be applied. The d-spacings observed for the intermediates were not consistent with staging processes, and molecular dynamics simulations suggested the intermediate phases to be a result of reorientation of the drug anions between the layers and/or varying hydration amounts. The HDS-drug composites were found to have sustained release profiles, and comply with pharmacopeia requirements in this regard.

The presence of $\mathrm{Ni}$ and $\mathrm{Co}$ in some of the systems reported in this work comprises a hurdle to their translation to the clinic. Although it is not believed that the materials reported here would be toxic (the amounts of HDS/drug composites required would free quantities of $\mathrm{Ni}$ and Co well below LD50 values, even if they dissolved fully), in our future work we will develop a series of HDSs using the most biocompatible metals possible.

\section{Acknowledgments}

The authors would like to thank: the Deutsches Elecktronen- Synchrotron for the provision of beamtime on DORIS, and Dr Joern Donges and Dr Andre Rothkirch for their assistance during in situ experiments on F3; Diamond Light Source for the provision of beamtime on 112 (EE7782), and Dr Michael Drakopoulos and Dr Christina Reinhard for their help and advice; and, Stephen Boyer of London Metropolitan University for elemental microanalysis measurements. Part of this work was done while AYAK was a visiting student at the Beijing University of Chemical Technology funded by the British Council China / China Scholarship Council Sino-UK Higher Education Research Partnership for PhD Studies, and we thank them for the award of this grant. Finally, A.Y.A.K. thanks his parents for financial and moral support.

\section{Supporting information available}

Additional XRD, IR data, MD and in situ data. 


\section{References}

1. Vialat, P. et al. High-performing monometallic cobalt layered double hydroxide supercapacitor with defined local structure. Adv. Funct. Mater. 24, 4831-4842 (2014).

2. Britto, S. \& Kamath, P. V. Polytypism in the Lithium-Aluminum Layered Double Hydroxides: The [LiAl 2 (OH) 6 ] + Layer as a Structural Synthon. Inorg. Chem. 50, 5619-5627 (2011).

3. Merchán, M. et al. Photostability and photobactericidal properties of porphyrin-layered double hydroxide-polyurethane composite films. J. Mater. Chem. B 1, 2139 (2013).

4. Bravo-Suárez, J. J., Páez-Mozo, E. a. \& Oyama, S. T. Review of the synthesis of layered double hydroxides: a thermodynamic approach. Quim. Nova 27, 601-614 (2004).

5. Oh, J.-M., Biswick, T. T. \& Choy, J.-H. Layered nanomaterials for green materials. J. Mater. Chem. 19, 2553 (2009).

6. Thomas, N. Mechanochemical synthesis of layered hydroxy salts. Mater. Res. Bull. 47, 3568-3572 (2012).

7. Yang, J. et al. New Inorganic-Based Drug Delivery System of Indole-3-Acetic Acid-Layered Metal Hydroxide Nanohybrids with Controlled Release Rate. Chem. Mater. 19, 2679-2685 (2007).

8. Kandare, E. \& Hossenlopp, J. M. Hydroxy double salt anion exchange kinetics: Effects of precursor structure and anion sizet. J. Phys. Chem. B 109, 8469-8475 (2005).

9. Morioka, H., Tagaya, H., Karasu, M., Kadokawa, J. \& Chiba, K. Preparation of hydroxy double salts exchanged by organic compounds. J. Mater. Res. 13, 848-851 (1998).

10. Williams, G. R., Crowder, J., Burley, J. C. \& Fogg, A. M. The selective intercalation of organic carboxylates and sulfonates into hydroxy double salts. J. Mater. Chem. 22, 13600 (2012).

11. Morioka, H., Tagaya, H., Kadokawa, J. I. \& Chiba, K. Studies on layered basic zinc acetate. J. Mater. Sci. Lett. 18, 995-998 (1999).

12. Rajamathi, J. T., Britto, S. \& Rajamathi, M. Synthesis and anion exchange reactions of a layered copperzinc hydroxy double salt, Cu1.6Zn0.4(OH)3(OAc)·H2O. J. Chem. Sci. 117, 629-633 (2005).

13. Tagaya, H., Sasaki, N., Morioka, H. \& Kadokawa, J. Preparation of New Inorganic-Organic Layered Compounds, Hydroxy Double Salts, and Preferential Intercalation of Organic Carboxylic Acids into Them. Mol. Cryst. Liq. Cryst. Sci. Technol. Sect. A. Mol. Cryst. Liq. Cryst. 341, 413-418 (2000).

14. Hara, T., Kurihara, J., Ichikuni, N. \& Shimazu, S. Size Control of Catalytic Reaction Space by Intercalation of Alkylcarboxylate Anions into Ni-Zn Mixed Basic Salt Interlayer: Application for Knoevenagel Reaction in Water. Chem. Lett. 39, 304-305 (2010).

15. Dong, L., Gou, G. \& Jiao, L. Characterization of a dextran-coated layered double hydroxide acetylsalicylic acid delivery system and its pharmacokinetics in rabbit. Acta Pharm. Sin. B 3, 400-407 (2013).

16. Al Ali, S. H. H. et al. Controlled release and angiotensin-converting enzyme inhibition properties of an antihypertensive drug based on a perindopril erbumine-layered double hydroxide nanocomposite. Int. J. Nanomedicine 7, 2129-2141 (2012).

17. Hussein, S. H. et al. Comparative study of Mg/Al- and $\mathrm{Zn} / \mathrm{Al}-$ layered double hydroxide-perindopril erbumine nanocomposites for inhibition of angiotensin-converting enzyme. Int. J. Nanomedicine 7, 
4251-4262 (2012).

18. Saifullah B, Hussein MZ, Hussein-Al-Ali SH, et al. Antituberculosis nanodelivery system with controlledrelase properties based on para-amino-salicylate-zinc amlunium-layered double-hydroxide nanocomposites. Drug Des Devel Ther 7, 1365-1375 (2013).

19. Barahuie, F. et al. Preparation and controlled-release studies of a protocatechuic acidmagnesium/aluminumlayered double hydroxide nanocomposite. Int. J. Nanomedicine 8, 1975-1987 (2013).

20. Berber, M. R., Minagawa, K., Katoh, M., Mori, T. \& Tanaka, M. Nanocomposites of 2-arylpropionic acid drugs based on Mg-Al layered double hydroxide for dissolution enhancement. Eur. J. Pharm. Sci. 35, 354-360 (2008).

21. Cao, F., Wang, Y., Ping, Q. \& Liao, Z. Zn-Al-NO3-layered double hydroxides with intercalated diclofenac for ocular delivery. Int. J. Pharm. 404, 250-256 (2011).

22. Choi, S. J. et al. In vivo anticancer activity of methotrexate-loaded layered double hydroxide nanoparticles. Curr Pharm Des (2013).

23. Richardson-Chong, S. S. D., Patel, R. \& Williams, G. R. Intercalation and Controlled Release of Bioactive Ions Using a Hydroxy Double Salt. Ind. Eng. Chem. Res. 51, 2913-2921 (2012).

24. Hussein, M. Z., Rahman, N. S. S. A., Sarijo, S. H. \& Zainal, Z. Herbicide-intercalated zinc layered hydroxide nanohybrid for a dual-guest controlled release formulation. Int. J. Mol. Sci. 13, 7328-42 (2012).

25. Moorhouse, S. J., Vranješ, N., Jupe, A., Drakopoulos, M. \& O’Hare, D. The Oxford-Diamond In Situ Cell for studying chemical reactions using time-resolved X-ray diffraction. Rev. Sci. Instrum. 83, 084101 (2012).

26. Williams, G. R., Norquist, A. J. \& O’Hare, D. Time-Resolved, In Situ X-ray Diffraction Studies of Staging during Phosphonic Acid Intercalation into [LiAl 2 (OH) 6 ]Cl·H 2 O. Chem. Mater. 16, 975-981 (2004).

27. Hammersley, A. P. FIT2D V9.129 Reference Manual V123.121. (1998).

28. Avrami, M. Granulation, Phase Change, and Microstructure Kinetics of Phase Change. III. J. Chem. Phys. 9, 177 (1941).

29. Avrami, M. Kinetics of Phase Change. I General Theory. J. Chem. Phys. 7, 1103 (1939).

30. Avrami, M. Kinetics of Phase Change. II Transformation-Time Relations for Random Distribution of Nuclei. J. Chem. Phys. 8, 212 (1940).

31. Erofe'ev, B. Generalized equation of chemical kinetics and its application in reactions involving solids. Compt Rend Acad Sci USSR 511-14 (1946).

32. Stählin, W. \& Oswald, H. R. The crystal structure of zinc hydroxide nitrate, $\mathrm{Zn} 5(\mathrm{OH}) 8(\mathrm{NO} 3) 2.2 \mathrm{H} 2 \mathrm{O}$. Acta Crystallogr. Sect. B Struct. Crystallogr. Cryst. Chem. 26, 860-863 (1970).

33. Accelrys Software Inc. Materials Studio 5.5. San Diego, USA (2010).

34. Andersen, H. C. Molecular dynamics simulations at constant pressure and/or temperature. J. Chem. Phys. 72, 2384 (1980).

35. Berendsen, H. J. C., Postma, J. P. M., van Gunsteren, W. F., DiNola, A. \& Haak, J. R. Molecular dynamics with coupling to an external bath. J. Chem. Phys. 81, 3684-3690 (1984). 
36. Allen, M. \& Tildesley, D. Computer simulation of liquids. (Clarendon Press, 1987).

37. Zhang, S. T., Yan, H., Wei, M., Evans, D. G. \& Duan, X. Valence force field for layered double hydroxide materials based on the parameterization of octahedrally coordinated metal cations. J. Phys. Chem. C 116, 3421-3431 (2012).

38. Casalini, T., Salvalaglio, M., Perale, G., Masi, M. \& Cavallotti, C. Diffusion and aggregation of sodium fluorescein in aqueous solutions. J. Phys. Chem. B 115, 12896-904 (2011).

39. Khan, A. I., Lei, L., Norquist, A. J. \& O’Hare, D. Intercalation and controlled release of pharmaceutically active compounds from a layered double hydroxide. Chem. Commun. (Camb). 2342-3 (2001).

40. Mohanambe, L. \& Vasudevan, S. Anionic clays containing anti-inflammatory drug molecules: comparison of molecular dynamics simulation and measurements. J. Phys. Chem. B 109, 15651-8 (2005).

41. Newman, S. P., Di Cristina, T., Coveney, P. V. \& Jones, W. Molecular Dynamics Simulation of Cationic and Anionic Clays Containing Amino Acids. Langmuir 18, 2933-2939 (2002).

42. Greenwell, H. C. et al. Interlayer Structure and Bonding in Nonswelling Primary Amine Intercalated Clays. Macromolecules 38, 6189-6200 (2005).

43. Wang, J., Kalinichev, A. G. \& Kirkpatrick, R. J. Effects of substrate structure and composition on the structure, dynamics, and energetics of water at mineral surfaces: A molecular dynamics modeling study. Geochim. Cosmochim. Acta 70, 562-582 (2006).

44. Xu, S.-M. et al. Understanding the thermal motion of the luminescent dyes in the dye-surfactant cointercalated ZnAl-layered double hydroxides: a molecular dynamics study. RSC Adv. 4, 47472-47480 (2014).

45. Evans, J. S. O., Price, S. J., Wong, H. V. \& O'Hare, D. Kinetic study of the intercalation of cobaltocene by layered metal dichalcogenides with time-resolved in situ X-ray powder diffraction. J. Am. Chem. Soc. 120, 10837-10846 (1998).

46. Kandare, E. \& Hossenlopp, J. M. Hydroxy double salt anion exchange kinetics: effects of precursor structure and anion size. J. Phys. Chem. B 109, 8469-75 (2005).

47. Millange, F., Walton, R. I. \& O'Hare, D. Time-resolved in situ X-ray diffraction study of the liquid-phase reconstruction of $\mathrm{Mg}-\mathrm{Al}-$ carbonate hydrotalcite-like compounds. J. Mater. Chem. 10, 1713-1720 (2000).

48. Perioli, L., Ambrogi, V., di Nauta, L., Nocchetti, M. \& Rossi, C. Effects of hydrotalcite-like nanostructured compounds on biopharmaceutical properties and release of BCS class II drugs: The case of flurbiprofen. Appl. Clay Sci. 51, 407-413 (2011).

49. Del Arco, M., Fernández, a., Martín, C. \& Rives, V. Solubility and release of fenbufen intercalated in

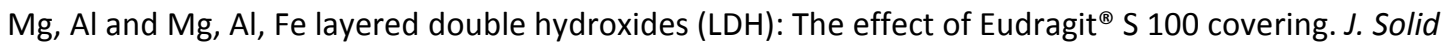
State Chem. 183, 3002-3009 (2010).

50. Perioli, L. et al. Intercalation and release of antiinflammatory drug diclofenac into nanosized ZnAl hydrotalcite-like compound. Appl. Clay Sci. 53, 374-378 (2011).

51. Gu, Z., Thomas, A. C., Xu, Z. P., Campbell, J. H. \& Lu, G. Q. In vitro sustained release of LMWH from MgAl-layered double hydroxide nanohybrids. Chem. Mater. 20, 3715-3722 (2008).

52. Barahuie, F., Hussein, M. Z., Abd Gani, S., Fakurazi, S. \& Zainal, Z. Anticancer nanodelivery system with 
controlled release property based on protocatechuate-zinc layered hydroxide nanohybrid. Int. J. Nanomedicine 9, 3137-3149 (2014).

53. Bull, R. M. R., Markland, C., Williams, G. R. \& O'Hare, D. Hydroxy double salts as versatile storage and delivery matrices. J. Mater. Chem. 21, 1822 (2011).

54. Ambrogi, V. et al. Eudragit ${ }^{\circledR}$ and hydrotalcite-like anionic clay composite system for diclofenac colonic delivery. Microporous Mesoporous Mater. 115, 405-415 (2008).

55. Delgado, D. R., Ruidiaz, M. A., Gómez, S. M., Gantiva, M. \& Martínez, F. Thermodynamic study of the solubility of sodium naproxen in some ethanol + water mixtures. Quim. Nova 33, 1923-1927 (2010).

56. Llinàs, A., Burley, J. C., Box, K. J., Glen, R. C. \& Goodman, J. M. Diclofenac Solubility: Independent Determination of the Intrinsic Solubility of Three Crystal Forms. J. Med. Chem. 50, 979-983 (2007).

57. Carriazo, D., del Arco, M., Martín, C., Ramos, C. \& Rives, V. Influence of the inorganic matrix nature on the sustained release of naproxen. Microporous Mesoporous Mater. 130, 229-238 (2010).

58. Arco, M., Fernández, A., Martín, C. \& Rives, V. Release studies of different NSAIDs encapsulated in Mg , Al , Fe-hydrotalcites. Appl. Clay Sci. 42, 538-544 (2009).

59. Rojas, R., Linck, Y. G., Cuffini, S. L., Monti, G. a. \& Giacomelli, C. E. Structural and physicochemical aspects of drug release from layered double hydroxides and layered hydroxide salts. Appl. Clay Sci. 109-110, 119-126 (2015).

60. Panda, H. S., Srivastava, R. \& Bahadur, D. In-vitro release kinetics and stability of anticardiovascular drugs-intercalated layered double hydroxide nanohybrids. J. Phys. Chem. B 113, 15090-15100 (2009).

61. Berber, M. R., Hafez, I. H., Minagawa, K., Mori, T. \& Tanaka, M. Nanocomposite formulation system of lipid-regulating drugs based on layered double hydroxide: Synthesis, characterization and drug release properties. Pharm. Res. 27, 2394-2401 (2010).

62. Kinget, R., Kalala, W., Vervoort, L. \& van den Mooter, G. Colonic drug targeting. J. Drug Target. 6, 12949 (1998).

63. Li, J. et al. In vitro evaluation of dissolution behavior for a colon-specific drug delivery system (CODES) in multi-pH media using United States Pharmacopeia apparatus II and III. AAPS PharmSciTech 3, E33 (2002).

64. The United States Pharmacopeia. In vitro and in vivo evaluation of dosage forms. (1995). 